
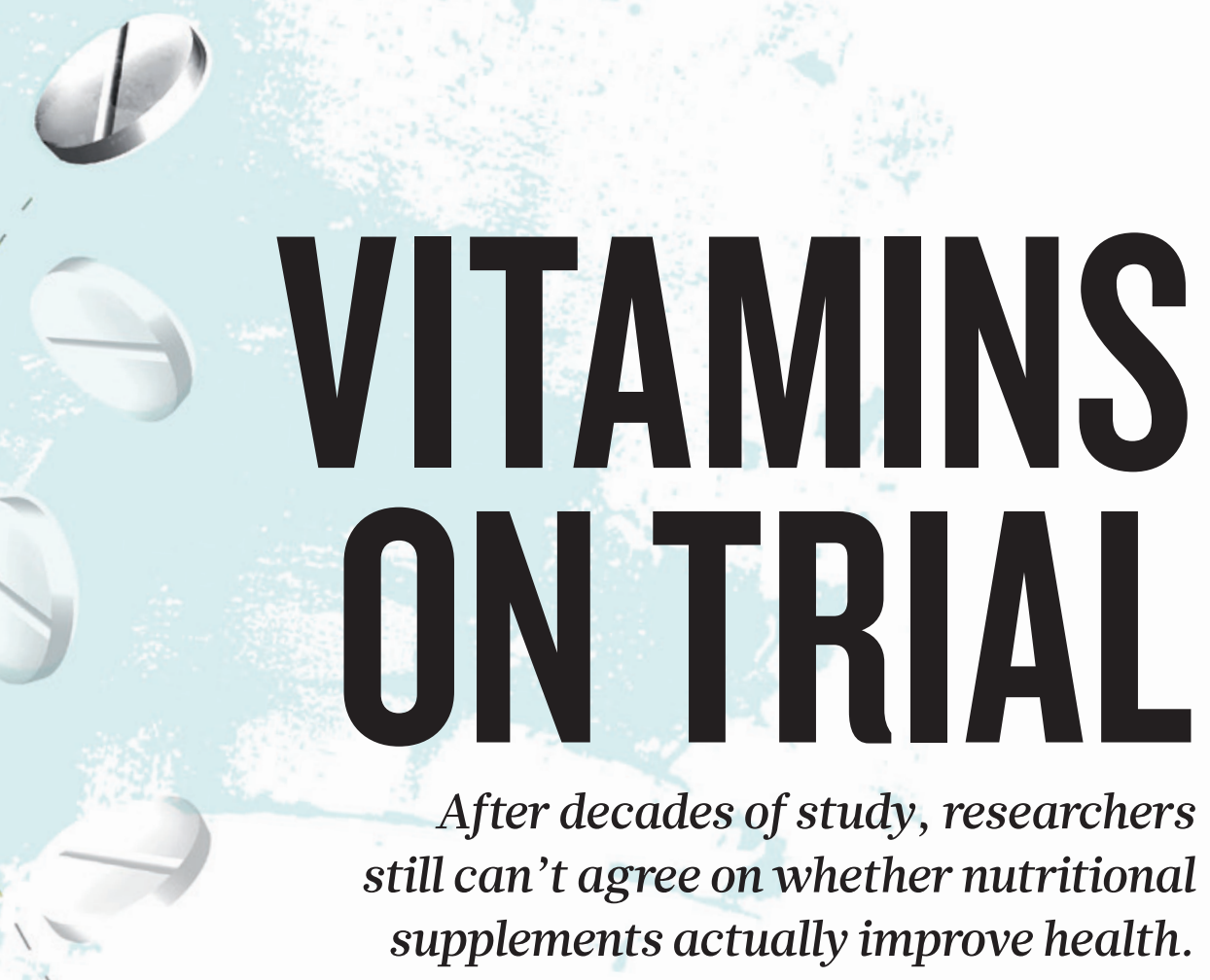

BY MELINDA WENNER MOYER

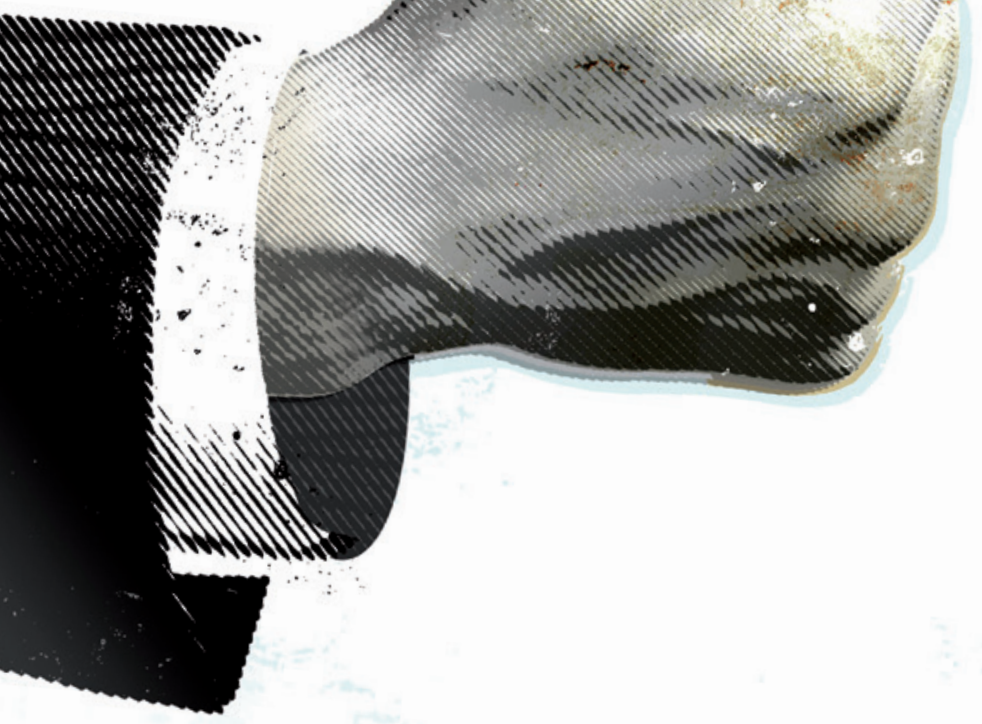

I

n 1911, Polish biochemist Casimir Funk discovered what was behind a then-mysterious neurological condition known as beriberi, common in regions where people's main source of calories came from de-husked, or 'polished', rice. He fed a group of ill pigeons a substance he had isolated from rice polishings, and within 12 hours, they had recovered. Funk went on to propose ${ }^{1}$ that a handful of puzzling ailments including beriberi and scurvy arose because of deficiencies in nutrients like the one he had found in the rice husks. He considered these chemicals vital amines, which he shortened to "vitamines".

Although many embraced the idea that vitamins could prevent or reverse certain illnesses, the medical establishment railed against it: Funk's colleagues at the Lister Institute of Preventive Medicine in London questioned his theory and tried to ban him from using the term vitamine in his papers, and a 1917 editorial in the Journal of the American Medical Association noted that although "the expression 'deficiency disease' has become popular", the concept is a "vague explanation that is readily accepted by the uncritical"2.

Today, nobody doubts that vitamin B1 can prevent beriberi or that vitamin $\mathrm{C}$ prevents scurvy. But scientific opinion about the use of vitamin supplements by millions of seemingly healthy people has never been more divided.

An editorial published in the Annals of Internal Medicine ${ }^{3}$ last year offers a striking case in point. In it, researchers at Johns Hopkins University in Baltimore, Maryland, and other institutions proclaimed with certainty that the US public should "stop wasting money" on vitamin supplements. They argued that research has found no benefits, in part because most people in industrialized nations are well-nourished. Within months a counterattack ensued, headed by huge names in nutrition science and biochemistry, including Bruce Ames at the Children's Hospital Oakland Research Institute in California and Walter Willett at Harvard University in Cambridge, Massachusetts, who argued that vitamin deficiencies are, in fact, widespread in the United States and 
that supplements can help to close nutritional gaps.

Meir Stampfer, an epidemiologist at Harvard, considers the anti-vitamin editorial "garbage". "I just felt sadness that such a poorly done paper would be published in a prominent journal and cause so much confusion," he says.

The argument raises important questions about the quality and relevance of more than a century of studies. "There will always be two polar sides to this argument, and the main reason for that is we don't know the answers - we don't have evidence one way or the other," says Paul Coates, who directs the Office of Dietary Supplements at the US National Institutes of Health (NIH) in Bethesda, Maryland.

Pooled together, evidence from doubleblinded, placebo-controlled clinical trials suggests that hardly any nutrient supplements have a consistent health effect on people in developed countries. But many argue that the null findings reflect research deficiencies, including poor study design, inappropriate mixing of different kinds of data and misunderstandings about how much of a nutrient is enough. "The tools we've had in the past have been so crude - it's like we've been looking through a dirty window with the curtains closed," says Susan Mayne, chair of the department of chronic disease epidemiology at the Yale School of Public Health in New Haven, Connecticut, and a member of the Institute of Medicine's Food and Nutrition Board, which establishes US nutrition guidelines such as the Dietary Reference Intakes for vitamins and minerals.

Although some scientists say that researchers can glean important insights from existing nutrition data, others, such as Robert Heaney, an endocrinologist at Creighton University in Omaha, Nebraska, argue that most existing studies are fatally flawed and that the whole enterprise needs a methodological overhaul.

"The trials we have in nutrition aren't answering the right questions, so they're not appropriate," says Connie Weaver, head of the department of nutrition science at Purdue University in West Lafayette, Indiana, and a member of the Food and Nutrition Board. "What we're using now is pretty bad science."

\section{THE SWEET SPOT}

The market for vitamins and supplements has been estimated at US\$68 billion worldwide and multivitamins are by far the most popular. Most people take them not to treat diagnosed deficiencies, but to improve or maintain "overall health", as reported ${ }^{5}$ last year by the Office of Dietary Supplements. Clinical deficiencies such as scurvy are rare in industrialized nations, but some research suggests that many people are at least mildly deficient in certain nutrients. In 2011, an analysis of data from the US Centers for Disease Control and Prevention's National Health and Nutrition Examination Survey (NHANES) reported ${ }^{6}$ that more than one-quarter of the US population are not getting enough of vitamins A, C, D and E, calcium or magnesium. Ninety-seven per cent fail to get enough potassium. The current Dietary Guidelines for Americans, released in 2010, warn that the intake of potassium, dietary fibre, calcium and vitamin D among the general public is "low enough to be of public health concern". Scientists argue over just how important these seemingly widespread subclinical deficiencies are. Johns Hopkins epidemiologist Pete Miller dismisses them as nonexistent. He argues that even with government-recommended nutrient levels, "the threshold for what defines deficiency is probably incorrect".

Surveys used to determine what kind of food people eat, and how much, are notoriously unreliable, for example. In 2013, a PLoS ONE study ${ }^{7}$ found that energy-intake data from the 39 years of NHANES studies were "not physiologically plausible" for a majority of participants because of systematic under-reporting.

Still for some nutrients, Mayne says, it is almost certain that some people are "really not getting enough". Moreover, research suggests that individuals with lower-than-average intakes but clinically 'normal' nutrient statuses could still benefit from supplements. Researchers at the Harvard School of Public Health recruited 672 health professionals with histories of benign colorectal tumours, a risk factor for colorectal cancer, to see if folic acid helped to reduce tumour recurrence. Half of are J- or U-shaped: nutrients have beneficial effects at low doses and toxic effects at high doses. The magnitude of the response differs, too, depending on where individuals start on the curve - their baseline status.

Yet this is often ignored. Many of the studies included in a 2009 systematic review ${ }^{10}$ commissioned by the US government to inform the development of guidelines for vitamin D intake, for instance, did not include information on baseline status, so the review probably lumped together individuals who responded differently; perhaps unsurprisingly, it concluded that findings on vitamin D were "inconsistent" (see Nature 475, 23-25; 2011). "These are common-sense design issues that need to be put on the table when you're thinking about a study, and they haven't been," says Heaney.

\section{MASKED EFFECTS}

Nutrient intake in control groups is also important but often overlooked. As part of the NIH's Women's Health Initiative (WHI), researchers tested the effects of daily doses of 1,000 mg of calcium a day - along with vitamin $\mathrm{D}-$ on women's fracture risks ${ }^{11}$. Although NHANES data at the time suggested that the average calcium intake for postmenopausal women was about $600 \mathrm{mg}$ a day, the trial investigators learned after randomization that women in the control group were actually consuming more than $1,000 \mathrm{mg}$ a day.

The trial found no statistically significant difference in fracture risk between the inter-

\section{"The tools we've had in the past have been so crude - it's like we've been looking through a dirty window with the curtains closed."}

the participants took 1 milligram of folic acid a day for between 3 and 6.5 years, and the other half took a placebo. The supplements had no effect when everyone was analysed together, but among the people with the lowest folic acid intake at the start of the trial, those who took supplements had a reduced risk of recurrence ${ }^{8}$.

On the other side of the coin, several large trials suggest that over-consuming nutrients could be dangerous. The Alpha-Tocopherol Beta-Carotene Cancer Prevention Trial set out to see whether smokers would benefit from certain supplements. It turned out that those who took $20 \mathrm{mg}$ of the vitamin A precursor $\beta$-carotene a day -3 times the US recommended daily allowance for vitamin $\mathrm{A}$ — for 5-8 years were, in fact, $18 \%$ more likely to develop lung cancer than those taking a placebo $^{9}$. A potential explanation is that the breakdown products of $\beta$-carotene can, at high doses, cause cell proliferation.

These results illustrate one of the many complexities of nutrient metabolism. Nutrition scientists now recognize that risk curves vention and control groups, but "the study design was such that it couldn't show anything", Heaney says. Even so, "systematic reviews continue to include the Women's Health Initiative as a 'negative' study".

The trial highlights two other potential confounding factors. The first is that study participants are typically more health-conscious than other individuals. Although WHI participants on average consumed relatively high levels of calcium, nearly $75 \%$ of US women between the ages of 31 and 50 fail to get the recommended $1,000 \mathrm{mg}$ of calcium per day from food. The second point is that compliance with instructions is often low - only $59 \%$ of participants were still taking at least $80 \%$ of their pills by the end. Those who do not stick to the prescribed treatments might differ from those who do in important ways, skewing outcomes.

Another important factor is genetic variability. "Every person has about 50,000 variations in their genes," says Steven Zeisel, director of the University of North Carolina Nutrition Research Institute in Chapel Hill. Any number 


\section{DATA DEFICIENCIES}

For almost every claim about vitamins, studies have found at least some negative evidence. But most of the negative findings have some confounding variables.

\section{"CHOLINE SUPPLEMENTATION BOOSTS FETAL BRAIN DEVELOPMENT."}

The negative finding: A doubleblind, randomized controlled trial ${ }^{15}$ involving 140 pregnant women found no enhancement to infant brain function.

The confounder: $44 \%$ of women have genetic variants that significantly increase their dietary choline requirement ${ }^{16}$.

\section{"CALCIUM AND VITAMIN D SUPPLEMENTATION REDUCES THE RISK OF BONE FRACTURES."}

The negative finding: The Women's Health Initiative calcium and vitamin $D$ trial $^{11}$ found no effect of supplementation on risk of hip fractures.

The confounder: Researchers had estimated that the control group was consuming less than $600 \mathrm{mg}$ calcium per day, when actual intake was more than 1,000 $\mathrm{mg}$.

\section{" $\beta$-CAROTENE REDUCES THE RISK OF COLORECTAL ADENOMA, A PRECURSOR TO COLORECTAL CANCER."}

The negative finding: A 1994 clinical study ${ }^{17}$ assigning 864 patients to different treatment groups that included $\beta$-carotene supplementation found no evidence of benefit, and some evidence of harm.

The confounder: Among nonsmokers and non-drinkers there was a significant decrease in the risk of adenocarcinoma, but smokers and drinkers had an increased risk ${ }^{18}$.

\section{"ANTIOXIDANT SUPPLEMENTATION REDUCES CANCER AND MORTALITY RISK."}

The negative finding: A metaanalysis ${ }^{19}$ of 21 clinical trials, covering a pooled sample of around 91,000 people and 8,800 deaths, found no evidence of an effect on mortality risk.

The confounder: The analysis did not stratify results by sex. Men may have been more likely than women to benefit from antioxidants ${ }^{20}$. of them could be important in metabolism. Yet "very few geneticists are collecting diet information, and very few diet people collect genetic information". Zeisel's work has uncovered, for example, that $44 \%$ of women have gene variants that significantly increase their dietary requirements for the nutrient choline. It is perhaps no wonder that trial results have been inconsistent - and that reviews often report null findings (see 'Data deficiencies'). Plus, the effects of nutrition interventions are probably subtle: whereas drug trials compare exposure with no exposure, nutrition trials compare higher and lower exposures, because everyone eats and consumes some nutrients. Subtle differences may be hard to detect and have long latency periods. These limitations and considerations add up "in a way that causes trials to be heavily stacked against showing any benefit", says biochemist Balz Frei, director of the Linus Pauling Institute at Oregon State University in Corvallis.

\section{A CLEARER VIEW}

So how can scientists design studies to arrive at nutritional truths? In a paper ${ }^{12}$ published in Nutrition Reviews in January, Heaney proposes guidelines. He argues that, first and foremost, scientists need to consider the dose-response curve. It is absolutely crucial, he says, to measure the baseline nutritional status of trial participants and track changes over time. He also suggests that investigators use participants with similar baseline intakes. That could limit who the results apply to, but it would make data clearer.

Measuring nutrient status presents additional challenges. Take calcium: the body carefully regulates blood levels, keeping them constant by pulling the mineral from bone when intake is low. Heaney says that it might be possible to measure how much is being consumed by looking at other biomarkers, such as parathyroid hormone, which triggers the removal of calcium from bone, but such tests can be expensive.

Researchers must also come up with accurate ways to assess food and nutrient intake during trials. This requires better estimates of the nutrients in foods. Frei says that the US Department of Agriculture's National Nutrient Database for Standard Reference, considered the country's authoritative source of foodcomposition data, overestimates the amounts of vitamin A in foods because the standard units used do not account for nutrient bioavailability. And it misses some other sources of vitamins in food. It does not, for example, assess levels of 25-hydroxycholecalciferol, a form of vitamin $\mathrm{D}$ found in animal products.

The good news is that scientists have developed technologies to improve measurements of both nutrient status and intake. Mayne and her colleagues, for instance, have created a skin-spectroscopy method for assessing levels of carotenoids ${ }^{13}$. "You can do it for zero cost, essentially - it's a 30-second scan on someone's skin that gives a readout of their nutrient status," she says. And researchers at Purdue are building a smartphone app that tracks food intake. Users take a picture of a plate of food, and the application estimates and records its nutritional components. These estimates have been shown to be more accurate than self-reports ${ }^{14}$.

Researchers also need to do better at considering and accounting for confounding factors. And reviews should be designed to answer specific questions about specific nutrient doses in specific populations, says Heaney - basically, they should include only those trials that "are appropriate for collapsing into a single data set". The Office of Dietary Supplements has sponsored a series of technical reports to investigate the challenges associated with evidence-based reviews in nutrition; six have been published.

So, back to the original question. Are supplements useless? The current state of research offers only an equivocal half-answer: 'maybe yes' for some individuals, nutrients and doses, and 'maybe no' for others. "Nutrition is complex, and I don't think we're necessarily going to find one formula that works for everybody," says Mayne. But new tools in development could "really change the way we look at this". The big question is whether, once scientists have all the pieces they need, they can put them together to create a clear and cohesive picture.

Melinda Wenner Moyer is a freelance writer in Cold Spring, New York.

1. Funk, C. J. State Med. 20, 341-368 (1912).

2. J. Am. Med. Assoc. 24, 2040-2041 (1917).

3. Guallar, E., Stranges, S., Mulrow, C., Appel, L. J. \& Miller, E. R. III Ann. Intern. Med. 159, 850-851 (2013).

4. Frei, B., Ames, B. N., Blumberg, J. B. \& Willett, W. C. Ann. Intern. Med. 160, 807 (2014)

5. Bailey, R. L., Gahche, J. J., Miller, P. E., Thomas, P. R. \& Dwyer, J. T. JAMA Intern. Med. 173, 355-361 (2013).

6. Fulgoni, V. L. III, Keast, D. R., Bailey, R. L. \& Dwyer, J. J. Nutr. 141, 1847-1854 (2011).

7. Archer, E., Hand, G. A. \& Blair, S. N. PLOS ONE 8 e76632 (2013).

8. Wu, K. et al. Am. J. Clin. Nutr. 90, 1623-1631 (2009).

9. The Alpha-Tocopherol, Beta Carotene Cancer Prevention Study Group N. Engl. J. Med. 330, 1029-1035 (1994).

10.Chung, M. et al. Evid. Rep. Technol. Assess. (Full Rep.) 183 1-420 (2009).

11.Jackson, R. D. et al. N. Engl. J. Med. 354, 669-683 (2006).

12. Heaney, R. P. Nutr. Rev. 72, 48-54 (2014)

13. Mayne, S. T. et al. Arch. Biochem. Biophys. 539, 163-170 (2013).

14. Lee, C. D. et al. J. Diabetes Sci. Technol. 6, 428-434 (2012).

15. Cheatham, C. L. et al. Am. J. Clin. Nutr. 96, 14651472 (2012).

16.Zeisel, S. H. Ann. Nutr. Metab. 60, 19-25 (2012)

17.Greenberg, E. R. et al. N. Engl. J. Med. 331, 141-147 (1994).

18.Baron, J. A. et al. J. Natl Cancer Inst. 95, 717-722 (2003).

19.Macpherson, H., Pipingas, A. \& Pase, M. P. Am. J. Clin. Nutr. 97, 437-444 (2012).

20. Hercberg, S. et al. Arch. Intern. Med. 164, 23352342 (2004). 